\title{
Unlocking Health Canada's cache of trade secrets: mandatory disclosure of clinical trial results
}

\author{
Matthew Herder LLM JSM
}

Competing interests: Matthew Herder has received reimbursement from Health Canada for travel expenses to attend consultations.

This article has been peer reviewed.

Correspondence to: Matthew Herder, Matthew.Herder@Dal.ca

CMAJ 2012. DOI:10.1503 /cmaj.110721
$\mathrm{H}$ ealth Canada should publicly disclose information about the safety and efficacy of pharmaceuticals, biologics and medical devices, and should especially disclose the designs and results of clinical trials. This disclosure is necessary to preserve public trust, ${ }^{1}$ address weaknesses in the evidence base ${ }^{2}$ and protect Canadians from harm. ${ }^{3}$

A prime example of the need for this disclosure involves selective serotonin reuptake inhibitors (SSRIs). Health Canada did not authorize SSRIs for sale to people younger than 19 years because of data from clinical trials showing risks of harm, including self-harm, associated with use of SSRIs in that age group. But Health Canada also did not publicly disclose that evidence, and by 2004 SSRIs were being widely prescribed for teenagers. Physicians had no idea they were invoking their discretion to prescribe "off label" on the basis of incomplete information - the balance of which Health Canada had in hand. ${ }^{4,5}$

Assessing how often harm results from nondisclosure is difficult because reporting of adverse events remains poor. ${ }^{6}$ What is clear from several analyses is that there is often a chasm between the published scientific literature (which is biased toward positive results) and the information that regulators possess about a given drug. ${ }^{2.7 .8}$

Why does Health Canada not divulge information from clinical trials until reports surface of widespread off-label prescribing? The reason is legal: the companies that manufacture these therapeutic products and devices claim that informa-

\section{- KeY POINTS}

- The law does not, in principle, preclude Health Canada from disclosing data on safety and efficacy associated with pharmaceuticals, biologics and medical devices, including data on the designs and results of clinical trials.

- The adversarial nature of the legal system, Health Canada's lack of action and the premium placed on commercialization by government, universities and the medical profession are barriers to greater openness.

- Canada should follow the lead of the United States' Food and Drug Administration and make the registration of clinical trials and disclosure of findings a mandatory requirement under Canada's Food and Drugs Act.

tion is "confidential business information" or a "trade secret," which they own, and which Health Canada is not free to disclose.

I witnessed this pas de deux while attending Health Canada's "technical discussions on regulatory modernization" held between October 2010 and January 2011. Each proposal put on the table by Health Canada to increase transparency - from making final decisions regarding applications for market authorization publicly available, to creating an online register of therapeutic products - was met with proprietary claims from MEDEC, BIOTECanada or Rx\&D, the respective associations of medical device, biotechnology and pharmaceutical companies in Canada. Each time, Health Canada acknowledged that the law controlled what they could and could not disclose.

In this article, I argue that the law, in fact, poses a minimal barrier to the disclosure of the designs and results of clinical trials. I begin by illustrating Health Canada's tendency to keep third-party information secret, then show why insofar as protecting third-party information has prevented the disclosure of the designs and results of clinical trials - this goes beyond what the law requires, in principle. I go on to highlight institutional barriers to changes in policy.

\section{Protect third-party information or Canadians?}

\section{The current situation}

Apart from what appears in the product monograph, the limited amount of data on safety and efficacy disclosed by Health Canada is in response to access to information requests made under the Access to Information Act. After a substantial increase in the number of requests during the 1990s, the number of new requests has plateaued (hovering in the neighbourhood of 1450 per year) during the last decade, although the volume of material associated with requests (measured by the number of pages of information evaluated per request) is on the rise (Table 1). ${ }^{9-14}$ 
These figures show nothing specific about Health Canada's willingness to disclose information about safety and efficacy. However, one relevant trend is discernable. Across instances in which all or some information is withheld on the basis of an exemption contemplated by the Access to Information Act, third-party information is by far the category of exemption most frequently invoked.

Four kinds of third-party information exist: trade secrets; confidential information; and information that, in the event of disclosure, may "be reasonably expected to" result in financial loss or prejudice a third party's "competitive position"; or interfere with "contractual or other negotiations." All four third-party exemptions seem well suited to denying public access to data on safety and efficacy submitted by manufacturers of biopharmaceuticals or medical devices.

\section{Help from the common law}

The courts have put boundaries on these four exemptions invoked under the Access to Information Act. To qualify as a trade secret in the eyes of the court, the information "must be of such peculiar value to the owner ... that harm to him would be presumed by its mere disclosure." ${ }^{15}$ Technical information such as the chemical composition and manufacturing processes of drugs have been found to be trade secrets, but not if such compositions and processes are common in the industry. ${ }^{16}$

Confidential information is broader in scope. But courts have put the onus on the party resisting disclosure to show that they have treated the information as confidential and, importantly, that "to do so is in the public interest.". 16 To assess the latter, courts have looked to the "nature of the relationship" between the third party and the governmental institution in question. The court has noted that Health Canada's role as a regulator reduces manufacturers' expectations of confidentiality, in contrast to other governmentindustry relations. ${ }^{16}$ The public interest, in other words, did not favour confidentiality.

The courts have also placed useful limitations on the other two exemptions related to thirdparty information, which focus on potential

Table 1: Publicly available information regarding access to information requests made to Health Canada, outcomes of requests and exemptions related to third party information invoked under section 20 of the Access to Information Act from 2000 to $2010^{-14}$

\begin{tabular}{|c|c|c|c|c|c|c|c|c|c|c|}
\hline & $2000 / 01$ & $2001 / 02$ & $2002 / 03$ & $2003 / 04$ & $2004 / 05$ & $2005 / 06$ & $2006 / 07$ & $2007 / 08$ & $2008 / 09$ & $2009 / 10$ \\
\hline New requests & 1345 & 1474 & 1367 & 1543 & 1363 & 1842 & 1442 & NA & 1158 & 1481 \\
\hline Requests processed & 1349 & 1537 & NA & 1353 & 1445 & 1538 & 1644 & NA & 950 & 1504 \\
\hline No disclosure & 114 & 93 & NA & 66 & 48 & 118 & 43 & NA & NA & 43 \\
\hline \multicolumn{11}{|c|}{$\begin{array}{l}\text { Exemptions invoked under the act, } \\
\text { by category }\end{array}$} \\
\hline $\begin{array}{l}\text { Responsibilities of } \\
\text { government }\end{array}$ & 74 & 85 & NA & 62 & 76 & 122 & 249 & NA & NA & NA \\
\hline $\begin{array}{l}\text { Operations of } \\
\text { government }\end{array}$ & 187 & 188 & NA & 162 & 147 & 185 & 363 & NA & NA & NA \\
\hline \multicolumn{11}{|c|}{$\begin{array}{l}\text { Exemptions invoked under the act, } \\
\text { by type of third party information }\end{array}$} \\
\hline Trade secrets & 117 & 124 & NA & 98 & 55 & 61 & 156 & NA & NA & NA \\
\hline $\begin{array}{l}\text { Confidential } \\
\text { information }\end{array}$ & 403 & 359 & NA & 343 & 356 & 380 & 560 & NA & NA & NA \\
\hline $\begin{array}{l}\text { Prejudicial } \\
\text { information }\end{array}$ & 398 & 340 & NA & 111 & 148 & 75 & 312 & NA & NA & NA \\
\hline $\begin{array}{l}\text { Contractual } \\
\text { information }\end{array}$ & 135 & 143 & NA & 28 & 34 & 10 & 175 & NA & NA & NA \\
\hline
\end{tabular}


harms to a company's competitive position or its business negotiations. First, the courts have deemed that more proof than mere assertions of harm by company officials is needed. Second, establishing harm is difficult when information is publicly available from other regulatory bodies, for example, the United States' Food and Drug Administration (FDA). ${ }^{16}$ Third, information, including reviewers' notes, that gives "insight into how government carries out its approval process is not the type of information which Parliament wished to exempt from disclosure." ${ }^{16}$ Fourth, information relevant to negotiations with provincial governments regarding inclusion on provincial drug formularies has been deemed by the court not to be within the meaning of "other negotiations." ${ }^{\prime 16}$ Finally, the court has concluded that disclosure of "specific methodological details including the inclusion and exclusion criteria used in clinical pharmacology trials, diagnostic parameters and outcome measurements" is not - without further evidence - harmful to a drug manufacturer. ${ }^{17}$

The latter finding does not resolve whether designs and results of clinical trials can, as a general rule, be disclosed. In fact, the court has never squarely considered whether the design and results of clinical trials fall within the Access to Information Act's exemptions related to thirdparty information because, in several instances, that information was already in the public domain or it had already been severed from the records Health Canada chose to disclose. ${ }^{16}$

\section{Treaties entered into}

Health Canada is constrained by other legal agreements. Memorandums of understanding with regulators in the United States, Europe and Australia all recite duties not to disclose proprietary information such as trade secrets. ${ }^{18-20}$ But none of these agreements define what a trade secret is. And in the absence of a court case on point, the decision to disclose data from clinical trials is left in the hands of national regulators. Whereas the FDA and, to a lesser extent, the European Medicines Agency have taken to openness, Health Canada, for reasons that are unclear, has not.

The North American Free Trade Agreement ${ }^{21}$ and the Agreement on Trade-Related Aspects of Intellectual Property Rights ${ }^{22}$ both support Health Canada's authority to disclose information where it is "necessary to protect the public" or other measures have been taken to preclude "unfair commercial use."

Both of these provisos seem to be met at present. Consider the latter: the so-called data protection regulation under the Food and Drugs Act provides an additional 8 years of "data exclusiv- ity" for "innovative drugs" (or 8.5 years for drugs suitable to pediatric populations). ${ }^{23}$ Ironically, commentators suggested as early as 1980 that data exclusivity - a set period during which one company is not allowed to secure regulatory approval for a product by relying on the safety and efficacy information previously supplied by another company for a "bioequivalent" product - was the best way to remedy any competitive harm that disclosure of data from clinical trials might cause. ${ }^{24}$ When data exclusivity was later added to Canada's Food and Drugs Act, courts read a loophole into the legislation such that establishing bioequivalence was deemed not the same thing as relying on the first mover's safety and efficacy data..$^{25}$ However, the Federal Court of Appeal recently closed that loophole. ${ }^{26}$ Thus, the Parliament of Canada has taken steps, which courts have sanctioned, to preclude unfair commercial use of data on safety and efficacy.

The alternative proviso, in which disclosure is permitted when "necessary to protect the public," may appear to set a high bar. However, several sources, including a parliamentary committee, note that Canadians may be "harmed by the lack of scrutiny and a dearth of independently assessed information." ${ }^{27}$ Evidence of actual harm following nondisclosure is, moreover, readily available, as shown in the previous example of SSRIs. A lack of openness about designs and results of clinical trials, coupled with inadequate oversight of offlabel use of drugs and adverse events, puts consumers of health products at risk..$^{28,29}$

Therein lies a deep incongruity with Health Canada's protection of industry's trade secrets, confidential information and the like. Trade secret laws evolved in response to competitive harm or unjust enrichment in the marketplace between business rivals previously bound by expectations of confidentiality, such as employer and employee. The focus is on wrongdoing among private parties. ${ }^{24}$ In the context of regulating controlled substances, other interests, most notably the welfare of Canadians, are in play.

In Canada and elsewhere, federal oversight of therapeutic products was a specific response to the patent medicines crisis. ${ }^{30,31}$ Protecting the safety and health of Canadians was and should remain Health Canada's social contract.

\section{Institutional barriers to policy change}

The law is a barrier to disclosure insofar as proceedings can continue for years (Figure 1), and the adversarial nature of the legal system can 
limit the court's perspective. No one, to date, has articulated for the court why the public interest favours access to safety and efficacy data beyond the confines of Health Canada. Those in a position to do so, such as the Canadian Medical Association or the Consumers' Association of Canada, should seek standing in proceedings under the Access to Information Act.

There are two more immediate institutional barriers to greater openness: institutional culture and inertia, and institutional mandate.

\section{Institutional culture and inertia}

Requests for information under the Access to Information Act are to receive a response within 30 days. However, months, if not years, can elapse before information is actually disclosed. The Information Commissioner of Canada has repeatedly sounded concerns over Health Canada's rate of deemed refusals. ${ }^{35}$ Roughly $20 \%$ of access to information requests filed with Health Canada are "carried over" to the next fiscal year or delayed beyond the 30-day, if not the extended, statutory deadline..$^{35}$

Health Canada claims to have undertaken a number of initiatives to increase transparency, but gains have been painfully slow to come about. ${ }^{36}$ Consider the Summary Basis of Decision project, which was intended to give Canadians insight into what informs Health Canada's decision-making (see Figure 1 for a timeline and Appendix 1, available at www.cmaj.ca/lookup /suppl/doi:10.1503/cmaj.110721/-/DC1, for fur- ther details about the project). ${ }^{32}$ It took 10 years for phase I of the project, limited to new drugs and (some) medical devices authorized for sale, to begin. Phases II and III have yet to begin, and an internal evaluation showed that uptake of the project has been poor within and beyond Health Canada owing to its limited contribution to information already in the public domain..$^{32,36}$

\section{Institutional mandate}

The shift to a globalized, knowledge-based economy has several implications. It helps to account for why medicine - as a profession appears less threatened by the appropriation of medical interventions and norms of secrecy than in the past. During the patent medicines era, members of the medical profession successfully lobbied for a legal bar on patenting "medical methods," including surgical techniques and methods of diagnosis. ${ }^{37}$ Today, medicine, governmental funding agencies and universities increasingly embrace commercialization goals and practices. $^{38}$

This shift also underlies the expansion in Health Canada's mandate. Whereas the inception of federal oversight was driven by harms resulting from consumption of patent medicines, the Health Canada of today describes itself as not just "protecting," but "promoting," the health of Canadians. That expansion in mandate may be generally acceptable given the breadth of Health Canada's program areas. However, when it comes to Health Canada's specific role in regu-

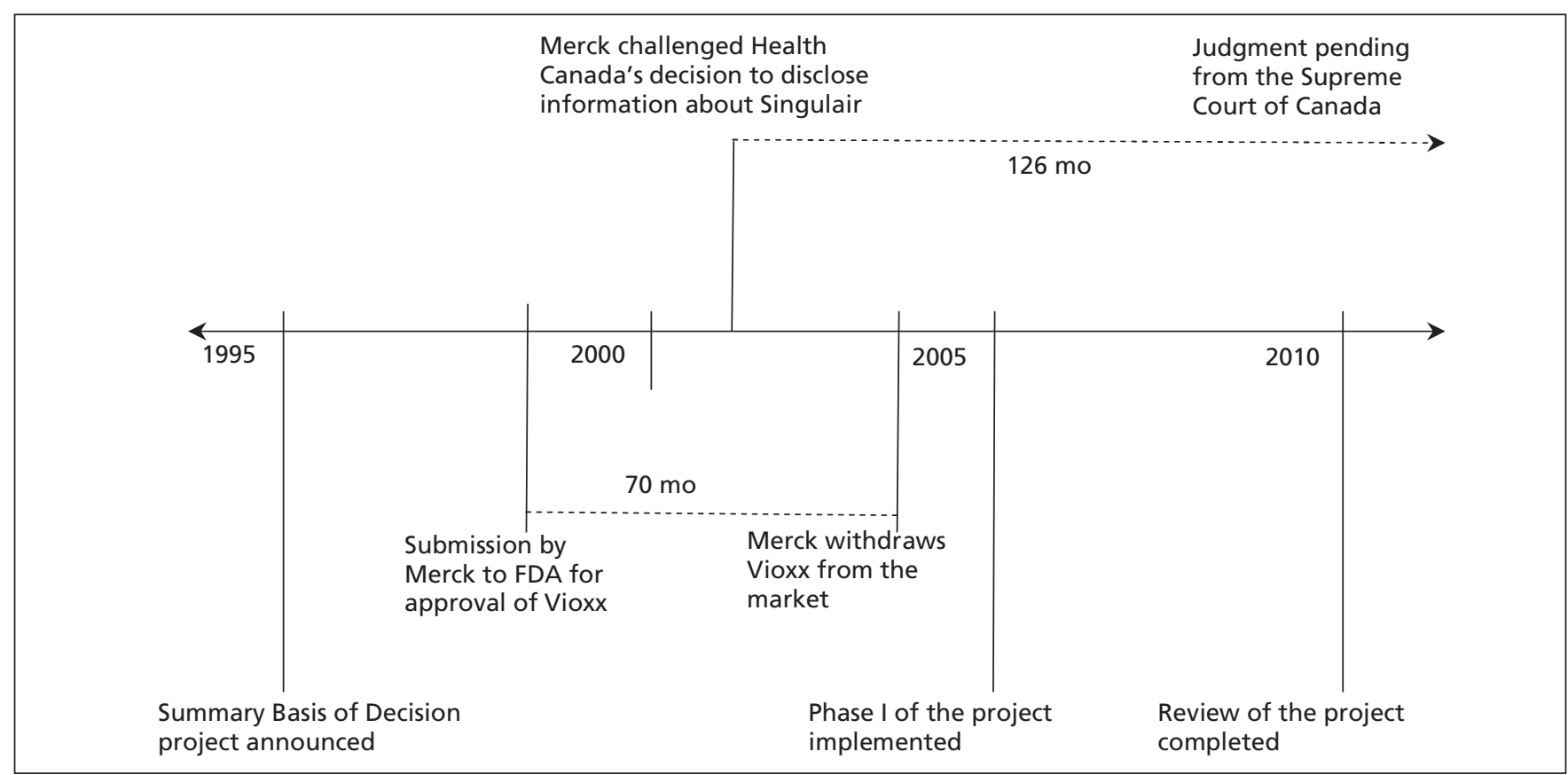

Figure 1: Timelines for Health Canada's Summary Basis of Decision project, the Vioxx proceedings and the ongoing litigation under the Access to Information Act between Merck and Health Canada regarding Singulair, an asthma medication. ${ }^{32-34}$

Note: FDA = Food and Drug Administration. 
lating pharmaceuticals, biologics and medical devices, there is a fundamental difference between Health Canada acknowledging that it as gatekeeper to the market - is part of a system of innovation and casting itself as a collaborator in the development of health products. The saga surrounding Merck's pained withdrawal of Vioxx from the market as well as ethnographic studies of Health Canada suggest that regulators can lose touch with that distinction. ${ }^{39,40}$ Keeping clinical trial data confidential indicates sympathy for industry's (unproven) claim that clinical trials secrecy is integral to the development of therapeutic products and devices.

\section{Make registration of clinical trials mandatory}

Concern that regulators are, in effect, working in tandem with members of the pharmaceutical, biotechnology and medical device industries is the driving force behind much of the controversy surrounding Health Canada's efforts to modernize its regulatory regime. ${ }^{41,42}$ Adopting a lifecycle approach - where pre- and postmarket exchange of information remains secret - does nothing to address concerns that the information on clinical trials tendered to Health Canada is, at best, incomplete and, at worst, doctored, as seen in the Paxil "study 329." ${ }_{43}$ Health Canada has failed to appreciate that its agreement to that arrangement, which has a tenuous basis in law, adds to the perception that it is industry-friendly.

The idea of requiring those who conduct clinical trials to register their trial designs and disclose their findings is not novel. ${ }^{44,45}$ Market incentives for manufacturers to manipulate evidence, coupled with Health Canada's resource constraints, make openness around clinical trial designs and data an essential component of biopharmaceutical and medical device regulation. At present, the law does not prevent Health Canada from disclosing data on clinical trials. To remove any lingering doubt, Health Canada should follow the FDA's lead and explicitly include that power in its future proposals to amend the Food and Drugs Act. Health Canada can profit from the FDA's three years of experience by creating a system that requires sharing not just more, but the right information to clarify rather than obfuscate, ${ }^{46}$ and protect the privacy of research participants.

Health Canada claims to have been exploring the requirements of registration of clinical trials and disclosure of results for some time. But such requirements were missing from Health Canada's most recent effort to amend the Food and Drugs Act, Bill C-51, which died on the order paper after first reading in 2008. When the issue was raised during Health Canada's 2010/11 "modernization" consultations, the moderator noted the issue on a flip chart dubbed the "parking lot" and urged participants to stick to the agenda. With Canadian Institutes of Health Research's recent questionable decision to withdraw its policy of clinical trials registration, ${ }^{47}$ Health Canada cannot continue to pass the buck. The law is no reason for further delay.

\section{References}

1. Dhalla I, Laupacis A. Moving from opacity to transparency in pharmaceutical policy. CMAJ 2008;178:428-31.

2. Turner EH, Matthews AM, Linardatos E, et al. Selective publication of antidepressant trials and its influence on apparent efficacy. N Engl J Med 2008;358:252-60.

3. Hébert PC, Stanbrook MB, MacDonald N, et al. Can Health Canada do better in protecting Canadians from unsafe drugs? CMAJ 2011;183:1125-6.

4. Silversides A. Transparency and the drug approval process at Health Canada. Women and Health Protection; 2005.

5. University of British Columbia Therapeutics Initiative. Antidepressant medications in children and adolescents. Therapeutics Letter 2004;52. Available: www.ti.ubc.ca/newsletter/antidepressant -medications-children-and-adolescents (accessed 2011 Aug. 17).

6. Baker GR, Norton PG, Flintoft V, et al. The Canadian Adverse Events Study: the incidence of adverse events among hospital patients in Canada. CMAJ 2004;170:1678-86.

7. Whittington CJ, Kendall T, Fonagy P, et al. Selective serotonin reuptake inhibitors in childhood depression: systematic review of published versus unpublished data. Lancet 2004;363:1341-5.

8. Rising K, Bacchetti P, Bero L. Reporting bias in drug trials submitted to the Food and Drug Administration: review of publication and presentation. PLoS Med 2008;5:e217; discussion e217.

9. Health Canada. Annual report on the administration of the Access to Information Act and the Privacy Act 2000-2001. Ottawa (ON): Health Canada; 2001.

10. Health Canada. Annual reports on the administration of the Access to Information Act and the Privacy Act 2001-2002. Ottawa (ON): Health Canada; 2002.

11. Health Canada. 2004-2005 annual report on the Access to Information Act and the Privacy Act. Ottawa (ON): Health Canada; 2005.

12. Health Canada. Annual report 2005-2006: Access to Information Act and Privacy Act. Ottawa (ON): Health Canada; 2006.

13. Health Canada: Annual report 2006-2007: Access to Information Act and Privacy Act. Ottawa (ON): Health Canada; 2007.

14. Health Canada Access to Information Act annual report 2009 2010. Available: www.hc-sc.gc.ca/ahc-asc/pubs/_atip-aiprp /2010info/index-eng.php (accessed 2011 July 7).

15. Société Gamma Inc. v. Department of the Secretary of State of Canada (1994), 79 F.T.R. 42

16. AstraZeneca Canada Inc. v. Canada (Health), 2005 FC 1451 , aff'd 2006 FCA 241

17. Canada (Minister of Health) v. Merck Frosst Canada Ltd., 2009 FCA 166 (decision at the Supreme Court of Canada is pending).

18. Memorandum of understanding between the Food and Drug Administration, Department of Health and Human Services of the United States of America and the Health Products and Food Branch, Health Canada, of Canada regarding sharing and exchange of information about therapeutic products. Ottawa (ON): Health Canada; 2009. Available: www.hc-sc.gc.ca/ahc-asc /intactiv/agree-accord/us-eu-sharing-diffusion-eng.php (accessed 2011 July 11).

19. Memorandum of understanding between the Health Products and Food Branch of the Department of Health of Canada and the European Directorate for the Quality of Medicines and Healthcare of the Council of Europe regarding conformity of substances for pharmaceutical use - Health Canada. Ottawa (ON): Health Canada; 2009. Available: www.hc-sc.gc.ca/ahc-asc/intactiv /agree-accord/europe-substances-eng.php (accessed 2011 July 11).

20. Memorandum of understanding between the Health Products and Food Branch — Health Canada — of Canada and the Therapeutic Goods Administration Department of Health and Ageing of Australia regarding therapeutic products. Ottawa $(\mathrm{ON})$ : Health Canada; 2009. Available: www.hc-sc.gc.ca/ahc-asc/intactiv/agree -accord/austral-therap-eng.php (accessed 2011 July 11). 
21. North American Free Trade Agreement Between the Government of Canada, the Government of Mexico and the Government of the United States, 17 December 1992, Can. T.S. 1994 No. 2, 32 I.L.M. 289 (entered into force 1 January 1994).

22. WTO Agreement on Trade-Related Aspects of Intellectual Property Rights, 15 April 1994, 33 I.L.M. 1197.

23. Food and Drug Regulations, C.R.C., c. 870, C.08.004.1

24. MGarity TO. Shapiro SA. The trade secrets status of health and safety testing information: reforming agency disclosure policies. Harv Law Rev 1980;93:837-88.

25. Bayer v. Canada (Attorney General) (1998), 84 C.P.R. (3d) 129 (F.C.).

26. Apotex Inc. v. Canada (Minister of Health) 2010 FCA 334

27. Opening the medicine cabinet: first report on health aspects of prescription drugs. Report of the Standing Committee on Health Ottawa (ON): House of Commons, Canada; 2004.

28. Herxheimer A, Mintzes B. Antidepressants and adverse effects in young patients: uncovering the evidence. CMAJ 2004;170:487-9.

29. US Government Accountability Office. Prescription drugs: FDA's oversight of the promotion of drugs for off-label uses. Washington (DC): The Office; 2008. Available: www.gao.gov /products/GAO-08-835 (accessed 2011 July 12).

30. Eisenberg RS. The role of the FDA in innovation policy. Mich Telecom Tech Law Rev 2007;13:345-88.

31. Brief history of drug regulation in Canada. Ottawa (ON): Health Canada; 2007. Available: www.hc-sc.gc.ca/dhp-mps /homologation-licensing/info-renseign/hist-eng.php (accessed 2011 Aug. 17)

32. Results of the evaluation of phase I of the Summary Basis of Decision project. Ottawa (ON): Health Canada; 2010. Available: www.hc-sc.gc.ca/dhp-mps/pubs/drug-medic/sbd_er_smd-eng.php (accessed 2011 Aug. 17)

33. Reuters. A time line of Vioxx. The New York Times 2005 Aug. 19. Available: www.nytimes.com/2005/08/19/business/19vioxx .timeline.html (accessed 2011 July 18).

34. Supreme Court of Canada - SCC Case Information - Docket 33290. Merck Frosst Canada Ltd. v. Minister of Health. Ottawa (ON): Supreme Court of Canada; 2009. Available: www.scc-csc .gc.ca/case-dossier/cms-sgd/dock-regi-eng.aspx?cas=33290 (accessed 2011 July 18)

35. Office of the Information Commissioner of Canada. Institutions assessed in 2007-2008 and reassessed in 2008-2009: Health Canada. In: 2008-2009 report card at a glance. Ottawa (ON): The Office. Available: www.oic-ci.gc.ca/eng/rp-pr_spe-rep_rap-spe rep-car_fic-ren_2008-2009_14.aspx (accessed 2011 July 7).

36. Lexchin J. Who's calling the tune: harmonization of drug regulation in Canada. Ottawa (ON): Canadian Centre for Policy Alter- natives; 2011. Available: www.policyalternatives.ca/publications /reports/who's-calling-tune (accessed 2011 Aug. 17).

37. Piper ST. The emergence of a medical exception from patentability in the 20th century [thesis]. Oxford (UK): University of Oxford; 2008.

38. Downie J, Herder M. Reflections on the commercialization of research conducted in public institutions in Canada. McGill Health Law Pub 2007;1:23-44.

39. Topol EJ. Failing the public health - rofecoxib, Merck, and the FDA. N Engl J Med 2004;351:1707-9.

40. Graham J, Jones M. Rendre évident : une approche symétrique de la réglementation des produits thérapeutiques. Sociologie et sociétés 2010;42:153-80.

41. McKie D. Too many drugs allowed on market: MP. CBC News 2001 Jan. 20. Available: www.cbc.ca/news/politics/story /2011/01/19/health-canada-drugs.html (accessed 2011 July 15).

42. Schafer A. A bitter pill: safety of drugs is threatened by looser approval process. Ottawa (ON): Canadian Centre for Policy Alternatives; 2011. Available: www.policyalternatives.ca/publications /monitor/bitter-pill (accessed 2011 July 15).

43. Jureidini JN, McHenry LB, Mansfield PR. Clinical trials and drug promotion: selective reporting of study 329. Int J Risk Saf Med 2008;20:73-81.

44. De Angelis C, Drazen JM, Frizelle FA, et al. Clinical trial registration: a statement from the International Committee of Medical Journal Editors. Ann Intern Med 2004;141:477-8.

45. Krleza-Jeric K, Chan A-W, Dickersin K, et al. Principles for international registration of protocol information and results from human trials of health related interventions: Ottawa statement (part 1). BMJ 2005;330:956-8.

46. Hirsch L. Trial registration and results disclosure: impact of US legislation on sponsors, investigators, and medical journal editors. Curr Med Res Opin 2008;24:1683-9.

47. Silversides A. Withdrawal of clinical trials policy by Canadian research institute is a "lost opportunity for increased transparency.” BMJ 2011;342: d2570. doi: 10.1136/bmj.d2570

Affiliations: Matthew Herder is with the Faculty of Medicine, Dalhousie University, Halifax, NS

Acknowledgements: This paper benefited greatly from feedback provided by Janice Graham, Joel Lexchin, Marc-André Gagnon, Graham Reynolds, Scott Halperin, Lynette Reid, the members of Novel Tech Ethics at Dalhousie University, and two anonymous reviewers.

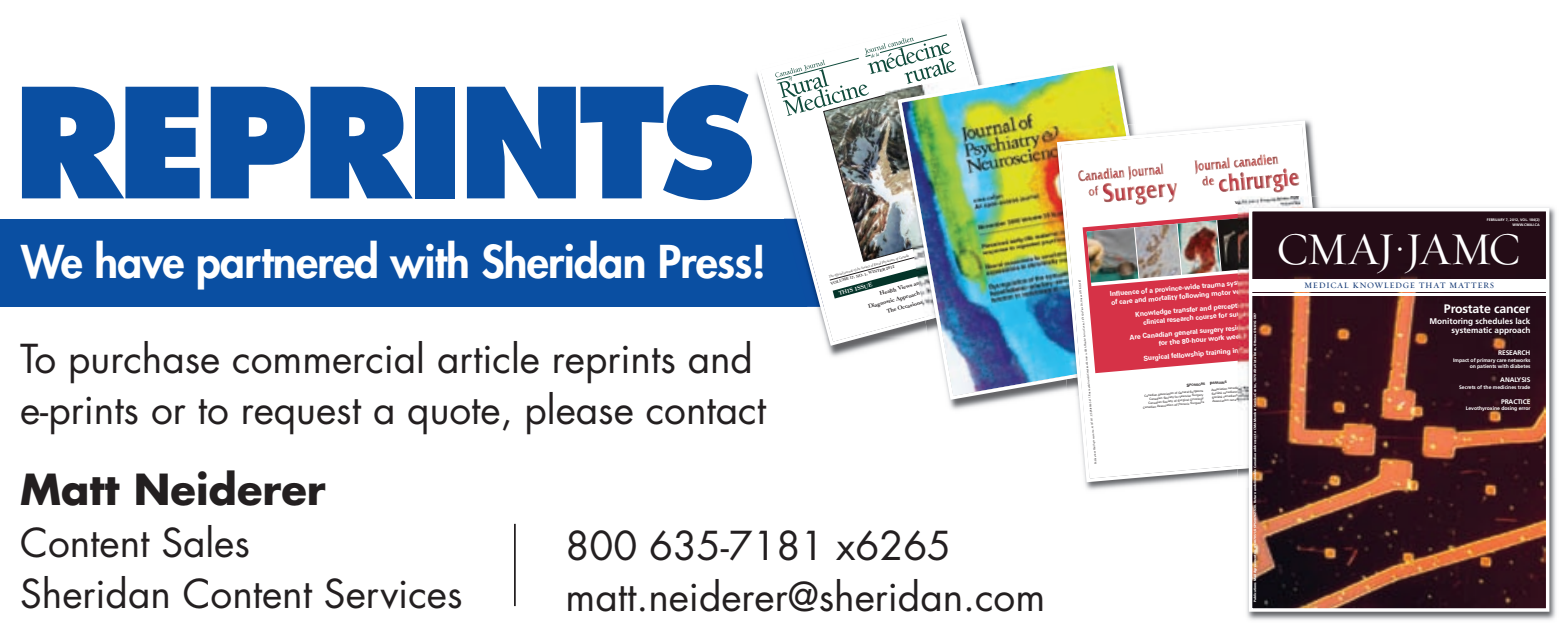

